\title{
Plastibell: A Safe Technique of Circumcision
}

\author{
Durr-i-Chaman'1, Tayyaba Fatima², Muhammad Akram³, Muhammad Yaqoob4 ${ }^{4}$ Sofia Irfan' ${ }^{5}$, Muhammad Sajid6 \\ 1,3,4,5,6Department of Surgery, Faisalabad Medical University, Faisalabad-Pakistan, 2Department of Surgery, Allied Hospital, Faisalabad-Pakistan,
}

\begin{abstract}
Background: Plastibell circumcision is safe alternative to open circumcision. Objective: The aim of this study is to review the safety and complications of plastibell circumcision as compare to other techniques reported in literature. Study Design: Retrospective Observational study. Settings: Private Sector Hospital, Faisalabad. Duration: January 2008 to December 2017. Methodology: 2576 cases including neonates and children up to 5 years of age circumcised in private clinic. Results: In $98.5 \%$ of cases there was no complication. In $1.5 \%$ of the cases complications like hematoma, bleeding, slipped ligature, retention of bell, urinary retention, infection and unsatisfactory results with less amount of prepural skin being removed were encountered. Conclusion: Plastibell circumcision is a safe technique with minimum complications in experienced hands and good alternative to open technique.
\end{abstract}

Keywords: Plastibell, Circumcision, Neonates.

Corresponding Author

Submitted for Publication: 29-04-2020

Accepted for Publication: 27-08-2020

Dr. Durr-i-Chaman, Assistant Professor, Department of Surgery, Faisalabad Medical University / Allied Hospital, Faisalabad-Pakistan.

Email: chaman.khan@yahoo.com

Citation: Chaman D, Fatima T, Akram M, Yaqoob M, Irfan S, Sajid M. Plastibell: A Safe Technique of Circumcision. APMC 2020;14(1):218-21.

DOI: $10.29054 / A P M C / 2020.812$

\section{INTRODUCTION}

Circumcision is surgical removal of prepuce that covers the glans penis ${ }^{5}$ Circumcision is a desirable public health intervention and an old custom being practiced in various communities for a long time..$^{1-14}$ It is one of the most common male surgical procedure performed globally with one in three males circumcised worldwide. It is performed in Muslim and Jew communities as a religious tradition with almost two-thirds of circumcised males worldwide being Muslims. ${ }^{1,2}$ There are clear advantages of early circumcision, preferably during the neonatal period with a clear correlation between complications and increasing age. The advantages include decreased incidence of urinary tract infections (UTI), faster healing, lower complication rate and cost effectiveness. ${ }^{1,2,3,4,6}$ The benefits also include reduced chance of HIV acquisition, HPV, penile warts, penile cancer and improved personal hygiene. $2,8,9,10,13$

There are different methods of pediatric circumcision e.g. the dorsal slit method, the Plastibell method, the Gomco clamp and the Mogen shield or clamp. ${ }^{7,8} \mathrm{I}$ infants the penis is small with a relatively undeveloped blood supply and post-operative penile erections are not a significant factor and these may be reasons why there has been widespread use of all these devices in infant circumcision in various countries but their use in adults remains experimental. ${ }^{7}$

The plastibell is a stay on disposable plastic ring with handle which is tightly tied on the foreskin and becomes detached and falls off naturally leaving a neat result and it comes in different sizes. ${ }^{5}$ Its use was first reported in 1956 . It is quick and effective method to achieve hemostasis and safe and easy to perform in infants using only local anesthesia with very few associated complications. ${ }^{6,7}$ Complications range from minor events such as oedema, surgical site infections, residual foreskin and retained ring to major complications such as ring slippage with primary hemorrhage, glansular gangrene and urethrocutaneous fistula. ${ }^{7}$

The aim of this paper is to review the complications of Plastibell circumcision reported in the literature and to review our own complications and to emphasis that it is a safe technique for circumcision with very low complication rate.

\section{METHODOLOGY}

Study Design: Retrospective Observational study.

Settings: Private Sector Hospital, Faisalabad.

Duration: January 2008 to December 2017.

Sample Technique: Simple random sampling technique.

Sample Size: 2576 patients.

Inclusion Criteria: All healthy neonates and children up to 5 years of age were included.

Exclusion Criteria: Neonates and children with Hypospadias, Epispadias, Webbed penis, Neonatal jaundice and congenital bleeding disorders are excluded from the study.

Data Collection Procedure: In this study neonates and children were operated by team of consultant surgeons. Preoperative examination, consent taking and explanation of procedure to the parents was done by operating surgeon.

The baby identified and restrained. The penis prepared with an antiseptic solution and local anesthesia dose of $1 \%$ Bupivacaine was calculated according to weight provided as penile block. The preputial ring dilated with a hemostat, foreskin retracted, all smegma removed and cleaned. Soft adhesions between glans and prepuce separated and the urethral meatus definitely identified. The foreskin grasped with hemostats at 10, 2 and 6 o'clock positions. A dorsal slit made at 12 o'clock position. The correct size Plastibell selected. The foreskin is pulled over the 
Plastibell which was stabilized by a hemostat clamping the skin to the handle of the Plastibell. The ligature applied on the Plastibell groove using a surgeon's knot for the first throw. The foreskin excised just past the outermost edge of the Plastibell taking care not to damage the glans. Final checking for bleeding, meatal opening and correct position of the ligature was performed at the end of the procedure. Post-operative Panadol drops were advised for pain relief. No antibiotics were prescribed. The parents were advised to watch for complications and strongly encouraged to come back to hospital in case of any problems and they were given contact numbers for any queries. The data of complications was collected from record of emergency visits of patients.

\section{RESULTS}

In our setup circumcisions are performed as part of religious custom. The size of Plastibell ring ranges from $1.1 \mathrm{~cm}$ to $1.7 \mathrm{~cm}$. Most common size used was $1.3 \mathrm{~cm}(43 \%)$ and next common being $1.4 \mathrm{~cm}(36 \%)$. Least used size was $1.7 \mathrm{~cm} \mathrm{(1 \% )} \mathrm{(Table} \mathrm{1).}$ Most circumcisions were performed in neonates (Table 2). On preoperative examination of the infants with hypospadias, local infection, systemic illness and physiological jaundice were excluded from the study. In two children of 4.5 and 5 years of age there was slippage of ligature and in both cases, it was reapplied. In seven cases there was hemorrhage due to peeling off of inner layer and converted to open circumcision. There was retention of bell in 5 cases which was removed manually. In five cases there was inadequate excision of foreskin and revision was done again by using plastibell. In four cases there was retention of urine and required emptying of bladder with fine catheter. In twenty cases mild infection was encountered with include indurated margins, odema of proximal skin and serous exudate from margins. In these cases, topical antiseptic cream containing fusidic acid was advised. In one febrile child of five years of age with local infection oral antibiotic syrup was also given.

\section{Steps of plastibell circumcision}

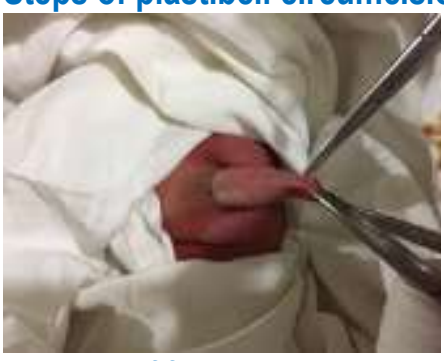

Holding of foreskin at 3 points

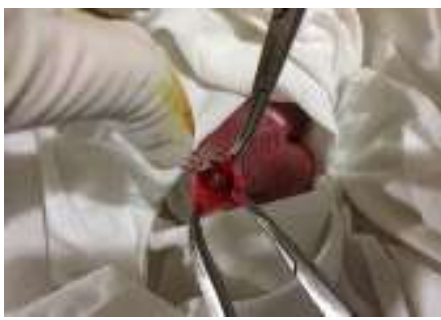

Plastibell with left hand

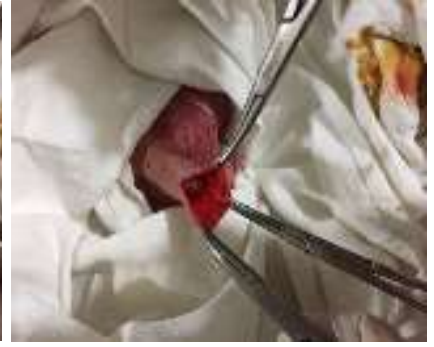

Making the dorsal slit

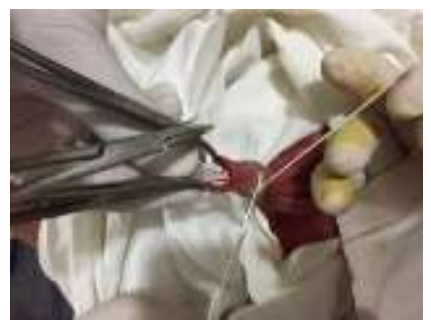

Tying up the ligature

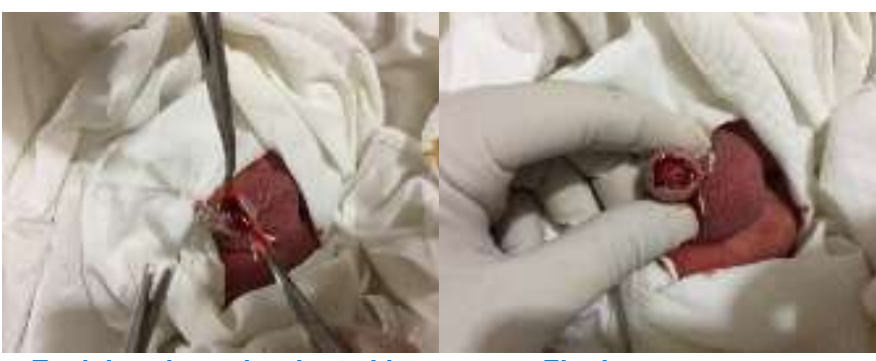

Excising the redundent skin

Final appearance

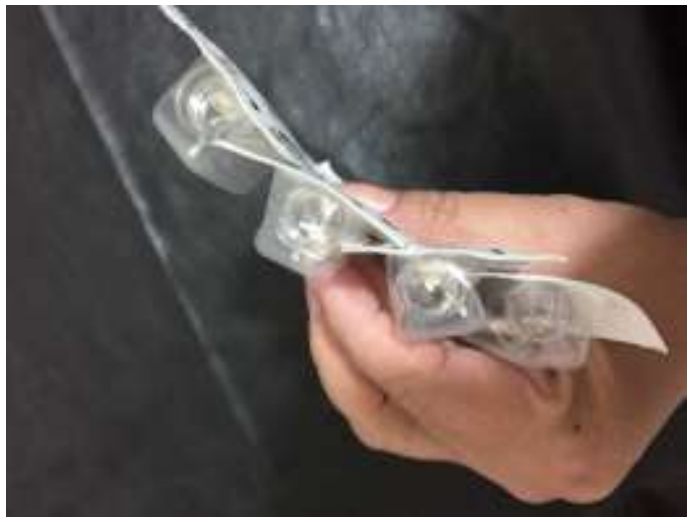

Different sizes of plastibell

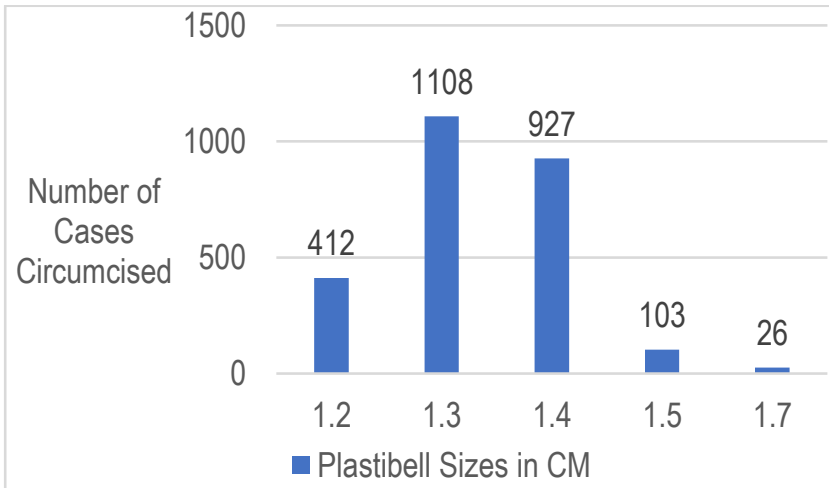

Figure 1: Plastibell sizes $(\mathrm{cm})$ used in circumcision of 2576 cases

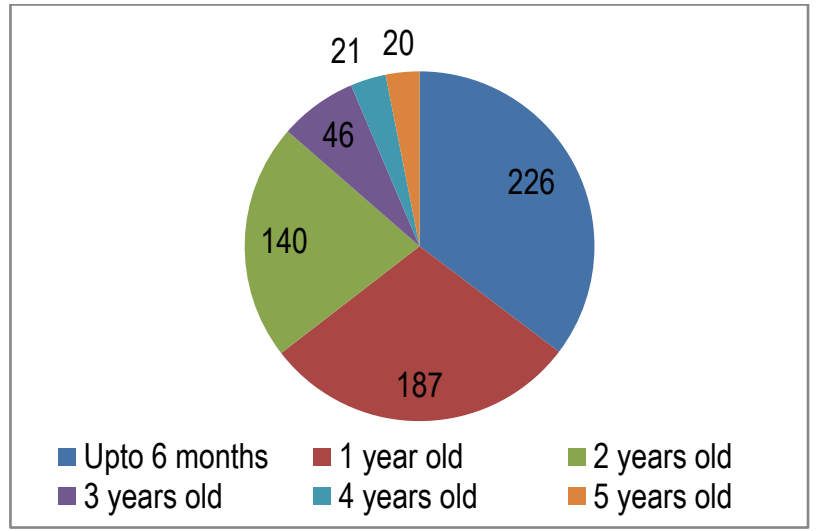

Figure 2: Age distribution in 2576 cases 
Table 1: Complications observed in 38 cases out of 2576 cases

\begin{tabular}{|l|c|}
\hline \multicolumn{1}{|c|}{ Complication } & Number of cases (\%) \\
\hline Hemorrhage & $7(0.27)$ \\
\hline Slippage of ligature & $2(0.07)$ \\
\hline Retention of urine & $4(0.15)$ \\
\hline Mild Infection & $20(0.77)$ \\
\hline Redo circumcision & $5(0.19)$ \\
\hline
\end{tabular}

\section{DISCUSSION}

Plastibell circumcision is a safe and simple method for circumcision in neonates and childern. ${ }^{7}$ There are many reasons to perform circumcision e.g. therapeutic, prophylactic, religious, cultural or social reasons. ${ }^{5,6}$ In our study $100 \%$ of the circumcisions were performed as a religious ritual. Studies conducted by Bioku Muftau Jimoh et al and Okechukwu Hyginus Ekwunife et al the religious indication for circumcision was 53\% and $59.3 \%$ respectively and cultural reason was $47 \%$ and $36.2 \%$ respectively. 5,7 We found out that the most common plastibell size deployed was $1.3 \mathrm{~cm}(43 \%)$ while $1.7 \mathrm{~cm}$ was the least commonly used ring (1\%).These results are similar to those reported by Bioku Muftau Jimoh et al, most common size used was $1.3 \mathrm{~cm}(45.7 \%)$ and least common was $1.6 \mathrm{~cm}(0.4 \%) .^{5}$ Complication rate of this procedure varies from $0.9 \%$ to $3.1 \%$ and can be upto $20 \%$ in some studies. $5,7,15,17$ Complication rate of conventional circumcision in literature is $3 \% .{ }^{17}$ In our study the complication rate is $1.5 \%$ which is almost half of the conventional circumcision complication rate and falls in lower range of complication rate of plastibell circumcision. There are many complications reported in the literature include proximal migration of the bell on to the distal penile shaft causing compression, hemorrhage, slippage of ligature, denution of penile skin, necrotizing fasciitis and dreadful complication of rupture of bladder due to urinary obstruction by the Plastibell. ${ }^{1,15} \mathrm{In}$ our study infection is the most common complication $(0.7 \%)$ followed by hemorrhage $(0.27 \%)$ which differs from literature in which hemorrhage is the most common complication ${ }^{15,16,17}$. The rate of infection is less than that reported by Seyed Abdollah Mousavi et al $(1 \%)$ and Carolina Talini et al $(1.2 \%))^{15,17}$ It is also less than the rate of infection in conventional circumcision reported in literature(4\%-14.9\%). The rate of hemorrhage in our study is $0.27 \%$ which is less than that reported by Carolina Talini et al(32.9\%), Seyed Abdollah Mousavi et al(18\%) Bioku Muftau Jimoh et al(48\%)and Sajid Razzaq et al(2.8\%).5,15,16,17 It is also significantly less than the rate of hemorrhage in conventional circumcision reported in literature(35\%). ${ }^{16}$ Complication of Penile stenosis is not reported in our study but study done by Sajid Razzaq et al, ${ }^{9}$ its rate is $22.8 \%$. The dreadful complication of urethral injury reported in literature by Okechukwu Hyginus Ekwunife et al $(0.7 \%)$ was not observed in our study. ${ }^{7}$ In our study redo circumcision was done in 5 cases due to inadequate foreskin removal and results are similar to those of Rebeca M Plank, MD et al in which 4 cases underwent redo circumcision. ${ }^{8}$

\section{CONCLUSION}

Plastibell circumcision is a safe procedure in experienced hands with few complications. Other than neonates it can be safely performed in older individual as well.

\section{LIMITATIONS}

At times there are problems with the availability of different sizes of Plastibell.

\section{SUGGESTIONS / RECOMMENDATIONS}

Local manufacturing of Plastibell can solve the issue of unavailability of plastibell.

\section{CONFLICT OF INTEREST / DISCLOSURE} None.

\section{ACKNOWLEDGEMENTS}

We acknowledge the administration of Saad Surgimed Hospital, Faisalabad for their help in collection and provision of data.

\section{REFERENCES}

1. Anwer AW, Samad L, Iftikhar S, Ansari NB. Reported Male Circumcision Practices in a Muslim-Majority Setting. Biomed Res Int. 2017; 2017: 4957348.

2. Hargreave T. Male circumcision: towards a World Health Organisation normative practice in resource limited settings. Asian J Androl. 2010;12(5):628-38

3. Morris BJ, Kennedy SE, Wodak AD, Mindel A, Golovsky D, Schrieber L, Lumbers ER, Handelsman DJ, Ziegler JB. Early infant male circumcision: Systematic review, risk-benefit analysis, and progress in policy. World J Clin Pediatr. 2017; 6(1):89-102.

4. Dave S, Afshar K, Braga LH, Anderson P. Canadian Urological Association guideline on the care of the normal foreskin and neonatal circumcision in Canadian infants (full version). Can Urol Assoc J. 2018;12(2):E76-E99.

5. Jimoh BM, Odunayo IS, Chinwe I, Akinfolarin OO, Oluwafemi A, Olusanmi EJ. Plastibell circumcision of 2,276 male infants: a multi-centre study. Pan Afr Med J. 2016; 23:35.

6. Morris BJ, Waskett JH, Banerjee J, Wamai RG, Tobian AA, Gray $\mathrm{RH}$, Bailis SA, Bailey RC, Klausner JD, Willcourt RJ, Halperin DT, Wiswell TE, Mindel A. A 'snip' in time: what is the best age to circumcise? BMC Pediatr. 2012;12:20.

7. Ekwunife $\mathrm{OH}$, Ugwu JO, Okoli CC, Modekwe VI, Osuigwe AN. Parental circumcision preferences and early outcome of plastibell circumcision in a Nigerian tertiary hospital. Afr J Paediatr Surg. 2015; 12(4):251-6.

8. Plank RM, Ndubuka NO, Wirth KE, Mwambona JT, Kebaabetswe P, Bassil B, Lesetedi C, Magetse J, Nkgau M, Makhema J, Mmalane M, Creek T, Powis KM, Shapiro R, Lockman S. A randomized trial of Mogen clamp versus Plastibell for neonatal male circumcision in Botswana. J Acquir Immune Defic Syndr. 2013; 62(5):e131-7.

9. Mavhu W, Mupambireyi Z, Hart G, Cowan FM. Factors associated with parental non-adoption of infant male circumcision for HIV prevention in Sub-Saharan Africa: a systematic review and thematic synthesis. AIDS Behav. 2014;18(9):1776-84. 
10. Sorokan ST, Finlay JC, Jefferies AL; Canadian Paediatric Society, Fetus and Newborn Committee, Infectious Diseases and Immunization Committee. Newborn male circumcision. Paediatr Child Health. 2015; 20(6):311-20.

11. Ince $B$, Gundeslioglu $A O$. A salvage operation for total penis amputation due to circumcision. Arch Plast Surg. 2013; 40(3):247-50.

12. Abdulwahab-Ahmed $A$, Mungadi IA. Techniques of male circumcision. J Surg Tech Case Rep. 2013;5(1):1-7.

13. Kenu E, Sint TT, Kamenga C, Ekpini R. Early Infant Male Circumcision in Cameroon and Senegal: Demand, Service Provision, and Cultural Context. Glob Health Sci Pract. 2016; 4 Suppl 1(Suppl 1):S18-28.

14. Chilimampunga C, Lijenje S, Sherman J, Nindi K, Mavhu W. Acceptability and feasibility of early infant male circumcision for HIV prevention in Malawi. PLoS One. 2017;12(4):e0175873.

15. Mousavi SA, Salehifar E. Circumcision complications associated with the Plastibell device and conventional dissection surgery: a trial of 586 infants of ages up to 12 months. Adv Urol. 2008;2008:606123.

16. Razzaq S, Mehmood MS, Tahir TH, Masood T, Ghaffar S. Safety of the plastibell circumcision in neonates, infants, and older children. Int J Health Sci (Qassim). 2018;12(5):10-13.

17. Talini C, Antunes LA, Carvalho BCN, Schultz KL, Del Valle MHCP, Aranha Junior AA, Cosenza WRT, Amarante ACM, Silveira AED. Circumcision: postoperative complications that required reoperation. Einstein (Sao Paulo). 2018;16(3):eAO4241.

\section{AUTHORSHIP CONTRIBUTION}

\begin{tabular}{|l|l|}
\hline $\begin{array}{l}\text { Dr. Durr-i-Chaman } \\
\text { Assistant Professor, Surgery } \\
\text { Faisalabad Medical University, } \\
\text { Faisalabad Pakistan }\end{array}$ & $\begin{array}{l}\text { Study Designing, Data Collection, } \\
\text { Results and Discussion Writing }\end{array}$ \\
\hline $\begin{array}{l}\text { Dr. Tayyaba Fatima } \\
\text { Senior Registrar, Surgery } \\
\text { Allied Hospital, Faisalabad Pakistan }\end{array}$ & $\begin{array}{l}\text { Help in Designing the Study, } \\
\text { Tabulation of Results, Designing } \\
\text { Charts and Figures }\end{array}$ \\
\hline $\begin{array}{l}\text { Dr. Muhammad Akram } \\
\text { Associate Professor, Surgery } \\
\text { Faisalabad Medical University, } \\
\text { Faisalabad Pakistan }\end{array}$ & Literature Review, Layout of \\
\hline $\begin{array}{l}\text { Dr. Muhammad Yaqoob } \\
\text { Assistant Professor, Surgery }\end{array}$ & Manuscript \\
Faisalabad Medical University, & Authentication of References \\
Faisalabad Pakistan & \\
\hline Dr. Sofia Irfan & \\
Assistant Professor, Surgery & \\
Faisalabad Medical University, & Statistical Analysis \\
Faisalabad Pakistan & \\
\hline Dr. Muhammad Sajid & \\
Professor of Surgery, & \\
Faisalabad Medical University, & Critical Review, Proof Reading \\
Faisalabad Pakistan & \\
\hline
\end{tabular}

